\title{
The Uneven Regional Pattern of Ecological Capital in Indonesia: A Political Economy Perspective
}

\author{
Bhimo Rizky Samudro ${ }^{1 *}$ \\ Harry Bloch ${ }^{2}$ \\ Ruhul Salim² \\ ${ }^{1}$ Faculty of Economics, Sebelas Maret University \\ Surakarta, Central Java \\ INDONESIA \\ ${ }^{2}$ School Economics and Finance, Curtin Business School, \\ Curtin University, Perth, WA 6845 \\ AUSTRALIA
}

${ }^{*}$ Corresponding author: Faculty of Economics and Business, Sebelas Maret University Indonesia, Phone: +62 81904025 330, Fax: +62 271 638143, E-mail: bhimosamudro@yahoo.com 


\title{
The Uneven Regional Pattern of Ecological Capital in Indonesia: A Political Economy Perspective ${ }^{1}$
}

\begin{abstract}
This study investigates the regional pattern of ecological capital in Indonesia through the principles of political economy. In this discourse, the gap between biocapacity and ecological footprint at the regional level (provinces) indicates the difficulties of environmental sustainability. Unevenness in ecological capital patterns occurs in Indonesian provinces as the gap between biocapacity and ecological footprint is heterogeneous. To demonstrate the causes of this unevenness, the regional pattern of ecological capital is scrutinized using the principle of hegemony, the principle of circular and cumulative causation (CCC) and principle of contradiction.
\end{abstract}

Keywords: political economy, ecological capital, uneven regional development JEL Classification:

\footnotetext{
1 An earlier version of this paper was presented to the $11^{\text {th }}$ International Conference Indonesian Regional Science Association (IRSA) Banjarmasin, Indonesia, 9-11 July 2012. The authors are grateful to conference participants as well as to Phil O'Hara for providing constructive comments. The usual disclaimer applies.
} 


\section{The Uneven Regional Pattern of Ecological Capital in Indonesia: A Political Economy Perspective}

\section{Introduction}

The notion of uneven development is used in the political economy perspective to understand economic performance. As Gerschenkron (1954) claims, most developing countries experience unevenness at the early stage of economic development. This stage includes several anomalies, led by the structural linkage between core and peripheral elements at regional level. Baran (1957) and Amin (1972) show that the core elements often hold sway over the peripheral elements in the process of economic development. Core elements typically use institutions to control the structural linkage between core and periphery. However, these institutions lead to transformation in socio-economic performances that promote contradiction rather than cumulative causation impacts on economic development.

At the national and regional levels, transformations occur as core regions dominate in the process of institutional change that generates heterogeneous patterns in multiple factors between the core and peripheral regions. The varying patterns occur not only in economic factors, but also typically occur in non-economic factors, including social, environmental and political factors. As Myrdal (1968) demonstrates, institutional change stimulates transformation on the circuit of multiple factors in an integrated system. Transformation of the non-economic factors may be more complex that of the economic factors as the uneven patterns of non-economic factors have incommensurable values and multiple proxies.

In Indonesia, the structural linkage between core and peripheral regions generate several anomalies as institutional changes are typically controlled from the core. These anomalies can be identified in multiple factors whose trends are heterogeneous, taking place in an uneven process of regional development. A group of regions may predominate in economic growth as GDP growth per capita rises, but they may show decreasing capacity in social and political factors. In contrast, several regions may show an increasing pattern in social capacity while experiencing declining economic growth. 
The uneven process of regional development in Indonesia also includes trends in environmental factors. These factors characteristically have indicators and incommensurable values that are difficult to measure. The structural linkages between environmental and other factors have endogenous processes that generate an increase in the magnitude of impacts (Kapp 1963, Berger 2008a, 2008b, 2009). In Indonesia, this increasing impact pattern is evident in the degradation of biocapacity in several provinces as the ecological footprint increases from economic development.

This gives rise to the questions addressed in this study. First, do uneven patterns in environmental factors, as represented by biocapacity and ecological footprint, occur in Indonesia? Second, what are the processes driving the pattern of biocapacity and ecological footprint in Indonesia? To investigate Indonesian patterns of biocapacity and ecological footprint, a political economy perspective is adopted.

The rest of this article proceeds as follows. Section 2 analyses the principles of political economy. An analysis on patterns of uneven ecological capital in Indonesia follows in Section 3. Section 4 concludes.

\section{Principles of Heterodox Political Economy: Hegemony, Circular and Cumulative Causation and Contradiction}

This section discusses several key principles of political economy critical to investigating research problems. The first is the principle of hegemony, or the principle of core, semiperiphery and periphery (C-SP-P), which focuses on the interrelationship among these elements in the world system. Core elements typically overcome those of the semi-periphery and periphery through hegemonic institutions (Baran 1957, Amin 1972, Wallerstein 1979). The structural linkages among these three elements lead to an endogenous process that generates contradictions in multiple factors of performance in semi-peripheral and peripheral elements.

The C-SP-P concept is employed by Raul Prebisch $(1950,1981)$ to analyze unequal advantages between the core and peripheral and semi-peripheral countries in world economic relations and cooperation. Prebisch argues that these unequal advantages cause the terms of trade decrease for raw materials produced by the peripheral countries. The terms of trade 
decrease for raw material products in the peripheral countries is influenced by the difference between the elasticity of relative income in manufacturing and that of raw material sectors. The demand of manufactured products is more elastic compared to raw material demand.

The difference in technological development can also cause the difference between core and peripheral countries in terms of the organization of the labor market and wage level. The technological change in the core countries has the potential to stimulate productivity and wage levels, simply because the well-established labor union supports it (Amin 1976; Korzeniewicz 2001). On the contrary, in the peripheral countries, the technological change stimulates competition between the company and the workers. The technological change in raw material production causes a decrease in both price and wage levels. Therefore, the difference in production organization between the core and peripheral countries becomes the cause for the unequal advantages of these two areas.

In addition to Prebisch, several other approaches analyze the relation of C-SP-P. Andre Gunder Frank (1967) states that economic surplus should be generated by the interconnection between the urban and rural area. Frank observes that economies of scale will continuously move from the urban areas to the rural areas. According to Frank's perspective, the transfer of economies of scale between urban and rural areas should occur so that those two areas can grow together simultaneously. Samir Amin (1976) characterizes economic performance in the peripheral countries. The peripheral countries tend to have a low productivity level of manufacturing, weak growth in the service sectors, inadequate access to international trade, and a low integration pattern of corporations among peripheral countries.

A different perspective in analyzing C-SP-P is offered by Wallerstein (1979, 2010a) and Arrighi, Silver, and Brewer (2003). This perspective emphasizes the access of each country to the exercise of economic and political power at the global level. In the world system, political power is seen as the ability to dominate the global economy. Moreover, Wallerstein and Arrighi introduce the position of semi-peripheral countries to distinguish them from core and peripheral countries in their access to prosperity. A country in the peripheral position can develop into the semi-peripheral when the country prospers. In this case, Wallerstein's perspective highlights the competitive pattern among countries in achieving access both politically and economically, rather than focusing on the relation pattern of productivity and trade among countries. 
As Arrighi, Silver and Brewer (2003) suggest, multiple indicators, including economic and non-economic factors, are employed in the stratification of C-SP-P. This model is useful in investigating the patterns of various indicators that represent transformation as institutional changes are controlled by core elements. As an example, a group of regions use economic institutions to control semi-peripheral and peripheral natural resources. This hierarchy model typically scrutinizes the hegemonic processes with institutional change in the core regions leading to contradictory situations in semi-peripheral and peripheral regions.

Hegemonic processes in Indonesian provinces are identified by the structural linkage between core and peripheral provinces. Core provinces in the west of Indonesia use institutions to hold sway over peripheral provinces in the east. The western provinces take over natural resources in the eastern provinces as most provinces in the west dominate financial institutions and have technology and innovation superior to the east. The hegemonic model between core and peripheral provinces in Indonesia is shown in Figure 1

\section{Figure 1 Hegemonic Model between Core and Peripheral Provinces in Indonesia.}

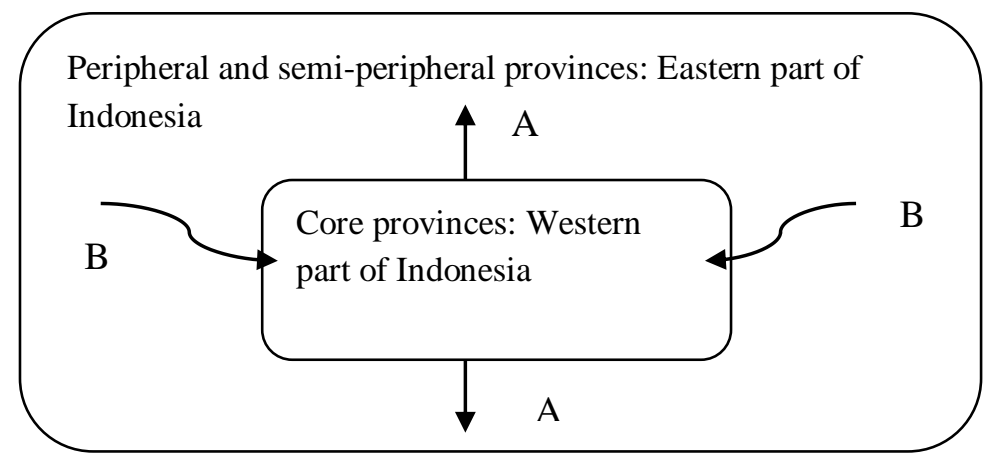

Note: Line A represents institutions that are used by core provinces to overcome the peripheral provinces, such as finance, technology and innovation; Line B represents the flow of natural resources and human resources from peripheral to core provinces.

The second principle of political economy to be used is circular and cumulative causation (CCC), which explains how at change in one factor leads to other factor changes in the same direction over time. This process generates cumulative causation, with positive feedbacks of impacts in a whole system. CCC describes a relation between a change of an independent variable and a change in a dependent variable. The dependent variable changes in accordance with change in the independent variable, in the same direction. More broadly, this answers the question of when a change in a variable causes a significant change in other variables in the socioeconomic system. A small change in the variables in the socioeconomic 
system will experience magnification when there is an income divergence at the global, regional, state, and individual levels.

Questions and discussions arise as to whether the CCC process occurs naturally or as a collective action. In answering such a question, discussion on CCC is directed toward the circularity aspect that becomes the focus of the cumulative process. To illustrate, when a change in variable A causes a change in variable B, but variable B's change does not give feedback to variable $A$, this process maintains an equilibrium in the system until the variable A's change ends. Conversely, an effect is cumulative when feedback moves and experiences magnification in the original variable (McCombie and Roberts 2009; Berger 2009b).

The process of CCC typically includes the interrelationship among multiple factors as both national and regional institutions change. Myrdal (1944, 1968) claims that the changes of social factors are led by the changes of economic factors in the same direction. Myrdal (1944) investigates racial inequality in the United States. He argues that 'lower classes' have a low education level, more children, less economic assets, and are risk averse. These characteristics lower classes' wage level and they subsequently face difficulties in obtaining a decent education level and savings access.

The result is supported by Myrdal's research in 1968. His analysis shows that lower wages cause lower nutrition and health, further producing a lower productivity level for the lower classes, which often results in a lower level of income.

Myrdal argues that access to a decent education level would enable lower classes to gain the opportunities to increase their living standard. The improved education level would increase their health, productivity, and income levels, and would decrease the social gap in society. This process is magnified when the education obtained is higher, and in turn also further develops health, productivity, and income. This then becomes the model for developing and under-developing countries to view education as an aspect that brings about a positive cumulative impact on social and economic development. The model of Myrdal's CCC is displayed in Figure 2. 


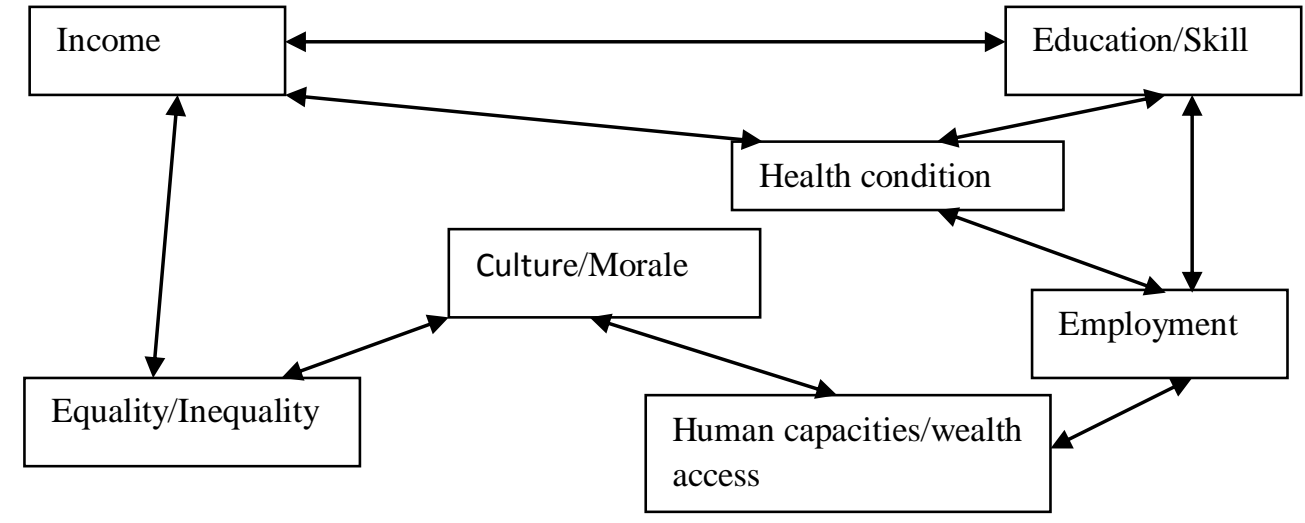

Figure 2 Myrdal's Model of Circular and Cumulative Causation Source: Developed from Myrdal (1944, 1968), O’Hara (2007), Berger (2009) and Sen (2011).

The structural linkage between core and semi-peripheral and peripheral provinces in Indonesia includes CCC. The pattern of CCC occurs in the structural linkage between core and peripheral provinces when natural and human resources provide the progress of economic development among provinces. The relationship of natural resources, human resources and technology creates an increasing magnitude of economic development in the long term. The pattern of CCC is displayed in Figure 3 below.

Figure 3 Circular and Cumulative Causation (CCC) Model between Core and Semi-peripheral and Peripheral Provinces in Indonesia

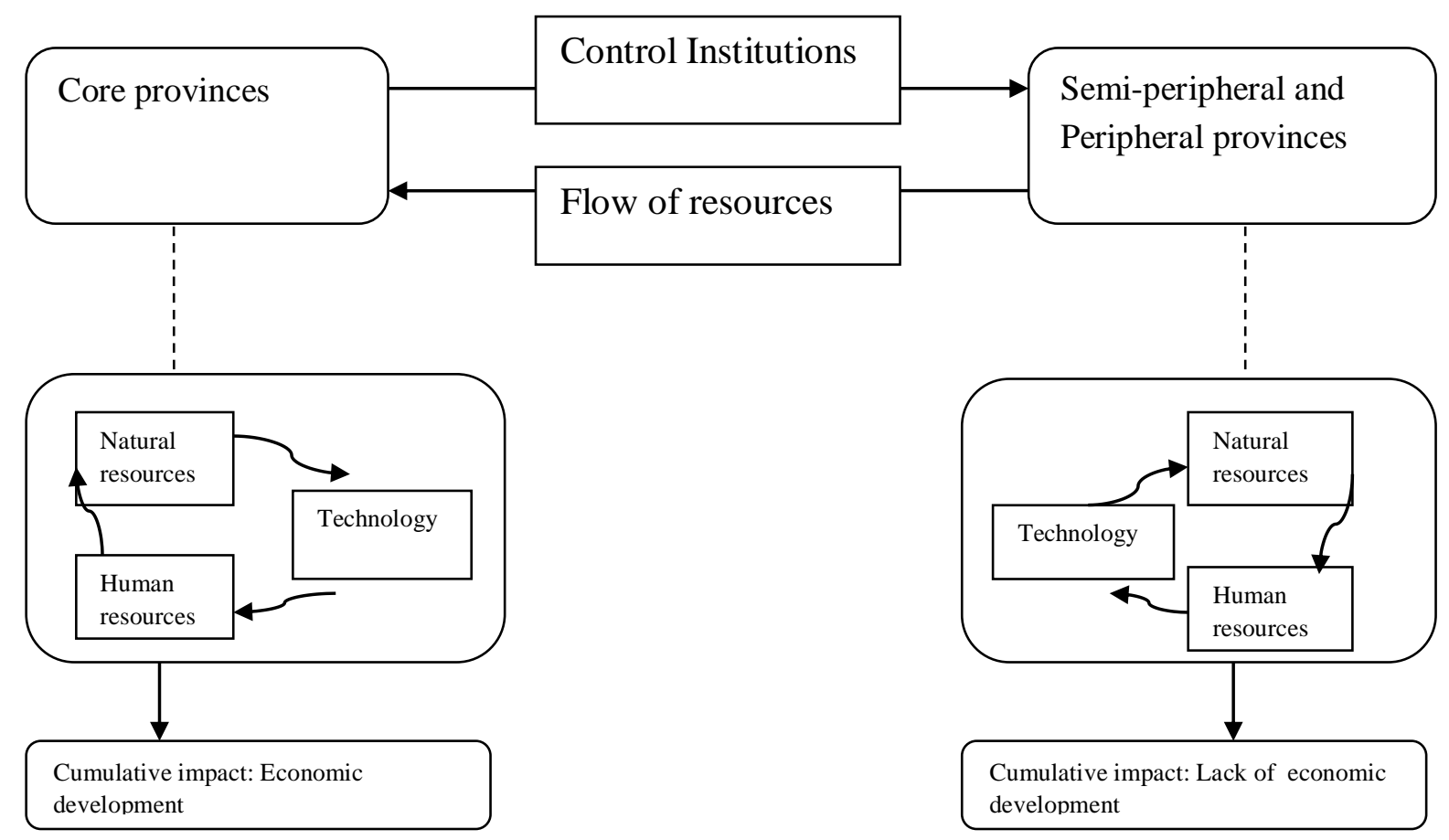


Linked to the principle of hegemony, the pattern of CCC experiences either the positive-positive direction or negative-negative. The core elements use institutions to maintain the structural linkage of C-SP-P that lead to increasing a factor that promotes the increase of other factors in the core. In contrast, semi-peripheral and peripheral elements undergo negative changes on multiple factors, as these elements have inadequate capacity to control institutions.

The third principle of political economy focuses on contradictions generated by endogenous process of structural linkages between multiple factors. A contradiction is an endogenous element in a system that moves simultaneously in both positive and negative directions (Glyn 1990; Foster 2005). Such contradiction occurs as a result of evolutionary and dynamic changes. The positive and negative aspects of the contradiction share characteristics in that they are related to economic transformation, are constantly and causally connected to other factors, contribute to the transformative development of long-term social economics, and experience particular pattern of cycles and trends in their evolution. The outcomes of this contradictory process are continuously changing over time, since this process is contingent on the institutions, behaviors, and interactions of the factors in the existing systems (Bell 1976; O'Hara 2010). The changes of outcome patterns can move progressively or regressively depending on those institutional pressures.

Glyn (1990, 1997) and Burkett (2006) put the process of contradiction that takes place in capitalist economies due to the linkages among the production system and the patterns of social and environmental factors. Capitalist economy is an economic system that undergoes continuous development in innovations and technologies to produce useful outputs for prosperity. However, when the worker's role is replaced by capital, a contradiction of capitalwork roles will occur. Effective demand will decrease, also resulting in a decrease of profit level.

Joseph Schumpeter (1939) observes another kind of contradiction in the development of capitalism: the contradiction between business innovation and the production focus of large companies. The development of capitalism is supported by innovative roles and technology development that produce new products. On the one hand, such a condition will increase profit levels and prompt the adoption of new production methods as a part of 
business cycles. On the other hand, the presence of large corporations will create oligopoly and tend to generate artificial patterns of innovations.

In the development of political economy theories, contradiction as a term is related to the concept of a disembedded economy. Karl Polanyi (1944) argues that capitalism is a system with innovation and productivity strengths, but the process has an impact on the social relation patterns between human beings and the environment. In the course of experiencing dynamic development, capitalism forges "creative destruction" by expanding the market and changing regulations, thereby creating productivity and profit. On the other hand, capitalism also continuously destroys social institutions and natural resources in its attempt to generate profit and productivity in the global system. Global institutions can evidently experience changes to support the development of capitalism in the long term. However, the contradictions resulting from such institutional changes can result in the decrease of growth.

In particular, the structural linkages between economic and environmental factors typically generate contradictions that promote an increasing magnitude of negative impacts in a whole system. O'Connor (1994) describes the notion of "two-stages" of contradiction, namely contradiction of capital-labor and contradiction of capital-environmental resources. The contradiction between capital and environmental resources regularly occurs in the same direction over time, generating cumulative of impacts. This is explained by Marx (1885) through the hypothesis of heat-death of the universe. Burkett (2006) shows that Marx's hypothesis is an extrapolation of contradictions that derives from a structural linkage between economic and environmental factors. For example, increasing economic growth that is promoted by institutions then stimulates declining environmental factors.

The relationship between core and periphery in Indonesia generates contradictions in the structural linkage between economic development and environmental factors at the provincial level. Contradiction occurs in one province when the pattern of economic development has a different motion from environmental factors. For instance, there is contradiction when a province has an increasing pattern in economic development and a declining pattern in ecological capital.

Figures 4 show the contradiction model between economic development and natural resources in Indonesian provinces. Core provinces use institution to control flow of resources from semi-peripheral and peripheral provinces to themselves. Consequently, core provinces 
experience high economic development, even though they have lack of natural resources. On the other hand, high natural resources in peripheral provinces are not followed by high economic development. In terms of contradiction, both core and peripheral provinces has contradiction between economic development and ecological capital.

Figure 4 Contradiction Model between Economic Development and Ecological Capital in Indonesian Provinces

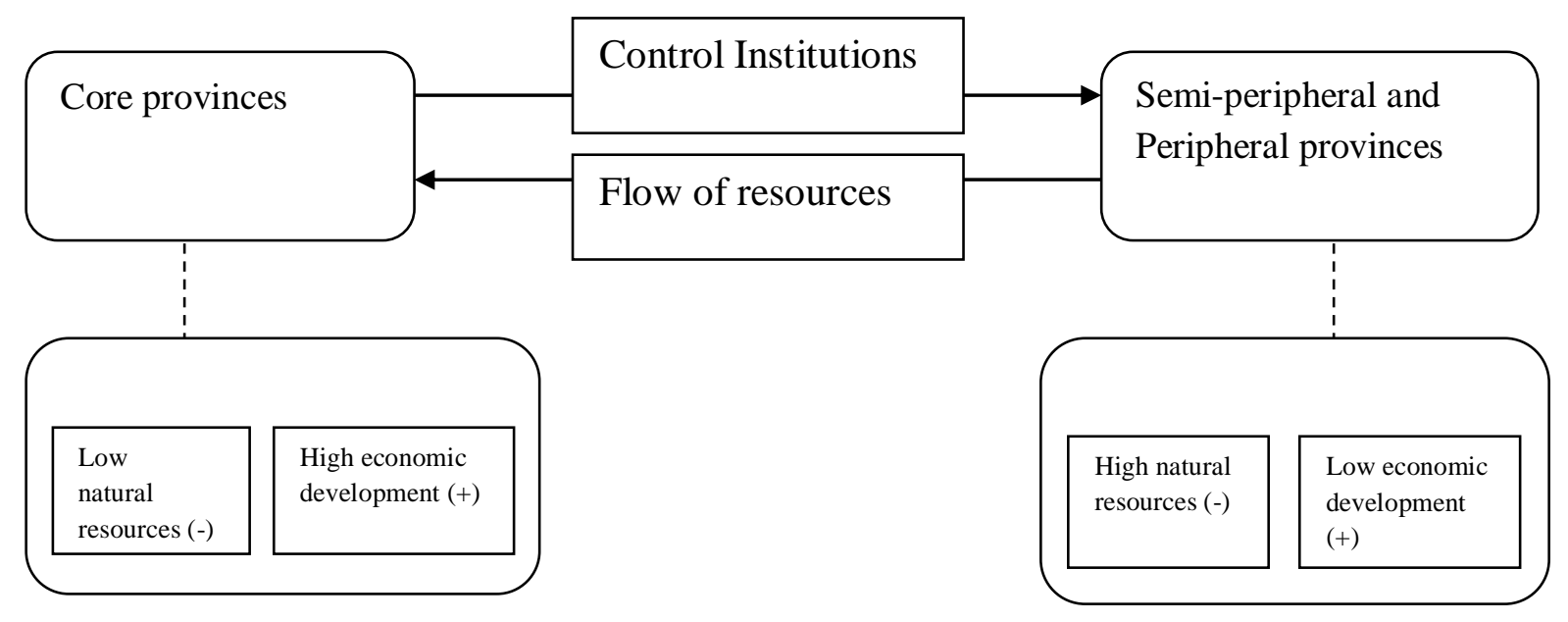

\section{The Uneven Regional Pattern of Ecological Capital in Indonesia}

This section describes the uneven regional pattern of ecological capital in Indonesia through two main analyses. The first is a hegemonic process analysis that captures the structural linkages of core, semi-peripheral and peripheral provinces in Indonesia. This first analysis identifies core provinces that use economic institutions to control ecological capital in semiperipheral and peripheral provinces. The second analysis examines the process of CCC and contradiction in the structural linkages between economic and environmental factors at the provincial level. Both CCC and contradiction may occur as core provinces lead institutional changes that influence the structural linkage of C-SP-P.

The specific indicators used for the stock of ecological capital, are the ecological footprint (EF) and biocapacity. EF is a measure of environmental demand as economies utilize ecological capacity to increase the supply goods and services (Goosens 2007, et.al: p 34). According to the Global Footprint Network (2010), EF captures the level of utilization of several basic components of ecological capital, including cropland footprint, grazing 
footprint, forest footprint, fishing ground footprint, carbon footprint and built-up land. In contrast, biocapacity is a measure of environmental capacity, so the gap between EF and biocapacity measures the change in ecological capital.

We examine the gap between EF and biocapacity in the 2000s at the regional level in a group of core, semi-peripheral and peripheral provinces in Indonesia to assess changes in ecological capital under uneven regional economic development. Figure 5 sets a forth fourquadrant analysis regarding biocapacity and ecological footprint among Indonesian provinces in 2010. This figure consists of four quadrants with four categorizations based on the gap between biocapacity and EF measures. Provinces above (below) the horizontal axis have an above (below) average EF, while those to the right (left) of the vertical axis have an above (below) average biocapacity.

In Figure 5 almost all core provinces are in the upper quadrants (Quadrant 1 and Quadrant 2), while almost all peripheral and semi-peripheral provinces are in lower quadrants (Quadrant 3 and Quadrant 4). As expected, the environmental footprint is relatively high in the core provinces, which reflects high relative levels of economic growth. In contrast, almost all peripheral and semi-peripheral provinces have relatively low EF, which reflects their relatively low economic growth. The distribution of biocapacity is less regular, with about even numbers of provinces above average (Quadrant 1 and Quadrant 4) and below average (Quadrant 2 and Quadrant 3) for both the core and non-core group of provinces. 
Figure 5 Four-Quadrant Analyses: Biocapacity and Ecological Footprint (gha per capita) 2010: Selected Provinces

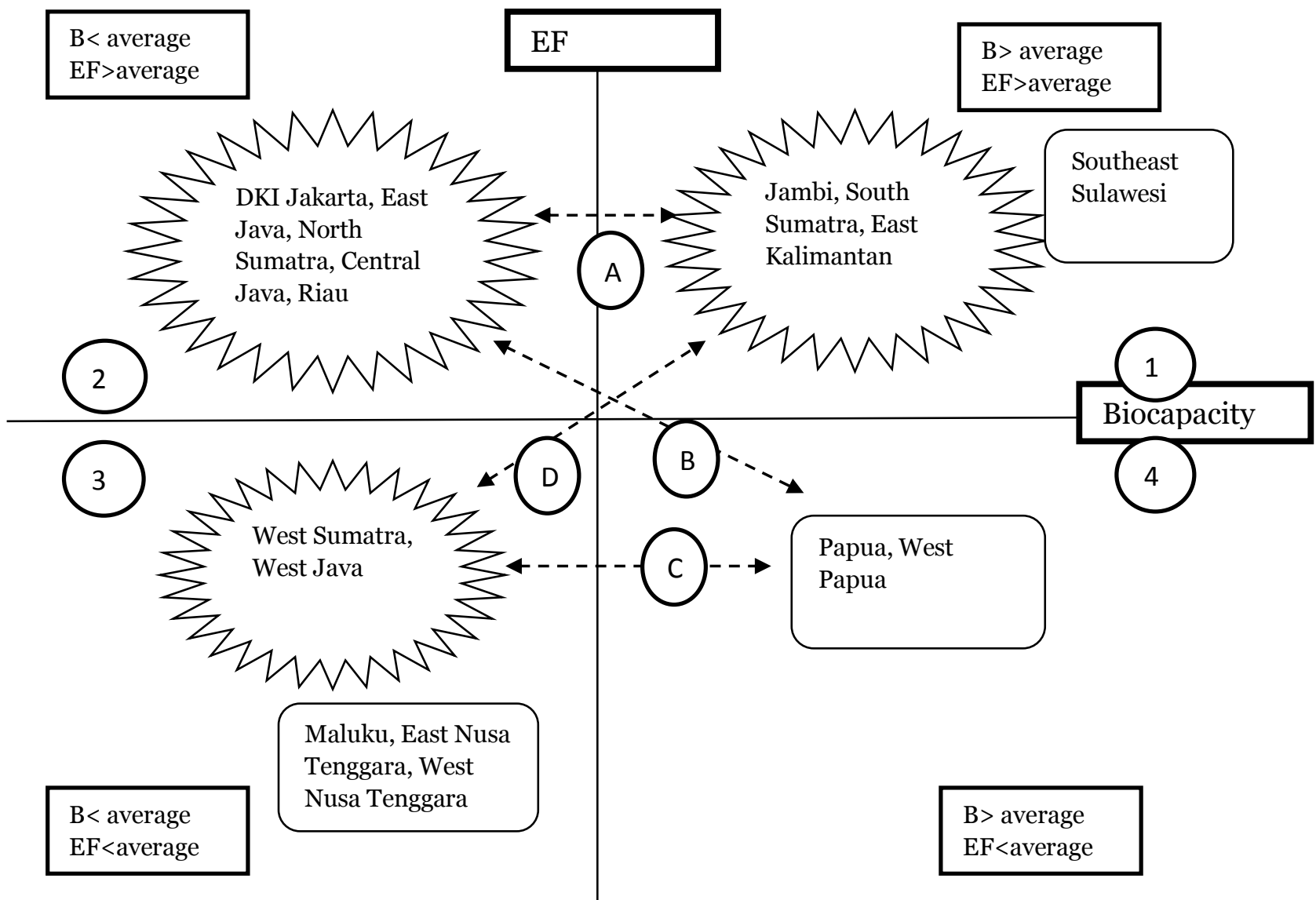

Source: Biocapacity and ecological footprint are calculated using period annual average based on Indonesian Ministry of Works. Note: Starboxes: Core provinces; Rounded-rectangle boxes: Semi-peripheral and peripheral provinces. Dashed-line: structural linkages of C-SP-P.

The core provinces in Quadrant 2 of Figure 4 face a contradiction between economic growth and a sustainable environment. They have above average economic growth, but are depleting their environmental capital through relatively high EF, which means high ecological demand, but have relatively low biocapacity. Two options are available for the core provinces in Quadrant 2 to overcome the contradiction. The first is that they maintain the structural linkages within core provinces, for example, dashed-line (A) shows that provinces in Quadrant 2 may have structural linkages to the core provinces in Quadrant 1 who have above average biocapacity. The second option is that they employ an economic institution to control the structural linkages with the semi-peripheral or peripheral provinces in Quadrant 4 (see dashed line B). This second option leads the structural linkages that generate anomalies in the semi-peripheral or peripheral provinces in the long term. According to current data, the semi-peripheral provinces of Papua and West Papua have relatively high biocapacity, 
However, a structural linkage to the core provinces that raises their EF may promote a contradictory situation that eventually leads to the erosion of their ecological capital.

In Quadrant 3 are both core and semi-peripheral or peripheral provinces experiencing biocapacity and ecological footprint below the national average. In this case, for core provinces (e.g. West Sumatra and West Java) may overcome the lack of biocapacity through the structural linkages within core provinces (see dashed-line D). These core provinces also have the opportunity to control the structural linkage between them and the semi-peripheral provinces in Quadrant 4 (see dashed-line C). In contrast, the semi-peripheral or peripheral provinces in Quadrant 3 are unlikely to achieve economic growth as they lack institutional capacity to control structural linkages.

In analyzing $\mathrm{CCC}$ and contradiction between economic development and ecological capital, Figures $6 \mathrm{a}$ and $6 \mathrm{~b}$ show the pattern of GDP growth per capita and ecological footprint per capita at the regional level. GDP growth per capita differences suggest unevenness in economic development among the provinces in Indonesia. Linked to contradiction, some provinces have high economic development, but their biocapacity is low. For instance, East Java has GDP growth per capita over 3.5 per cent, but its biocapacity is below 1 gha/capita. Conversely, GDP growth per capita in Central Kalimantan is below 3 per cent, but it has biocapacity over 7 gha per capita.

Figure 6a The Pattern of GDP Growth Per Capita in Indonesian Provinces During the 2000s (\%)

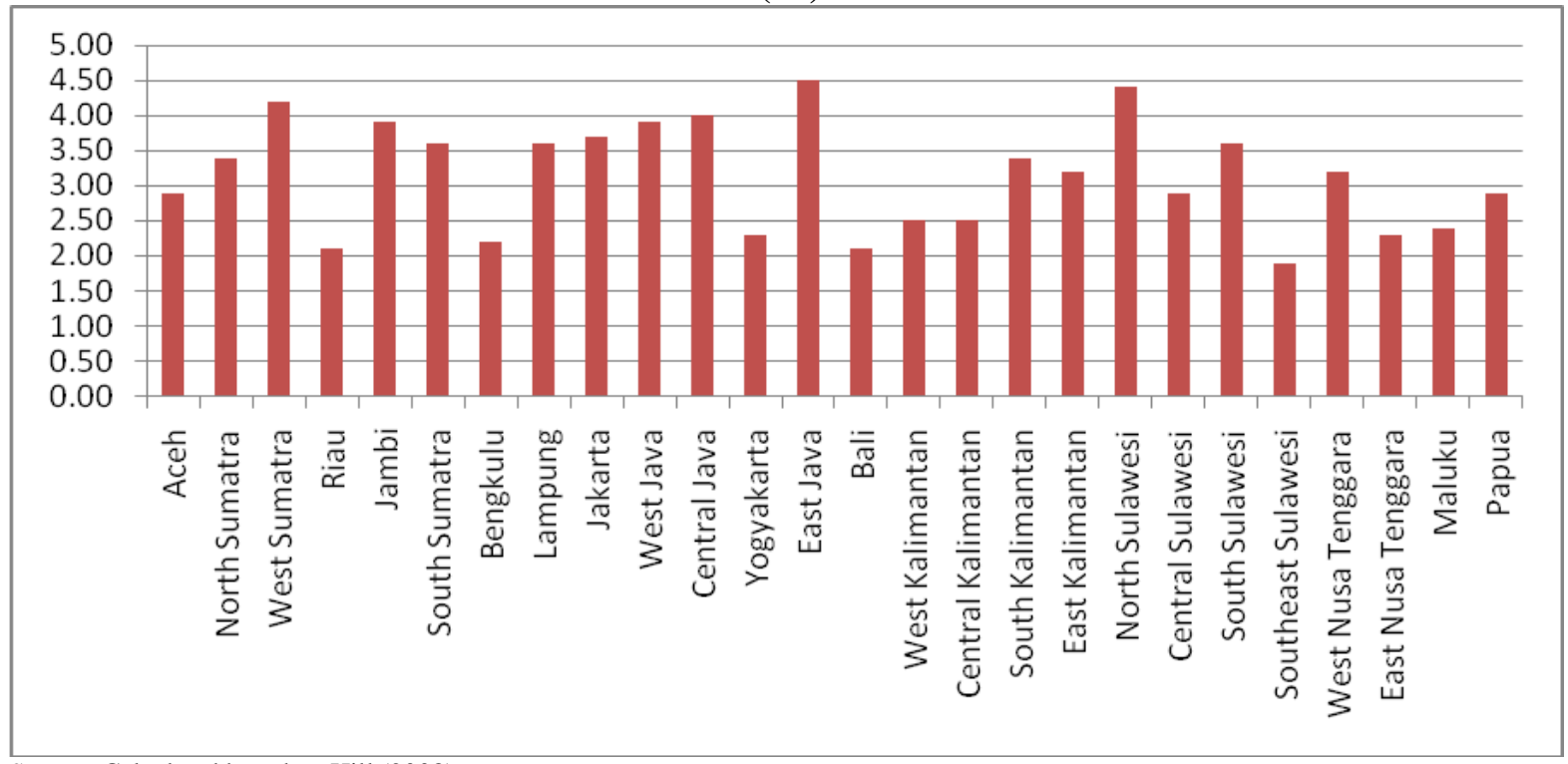

Source: Calculated based on Hill (2008) 
Figure 6b The Pattern of Biocapacity in Indonesian Provinces During the 2000s (gha/per capita)

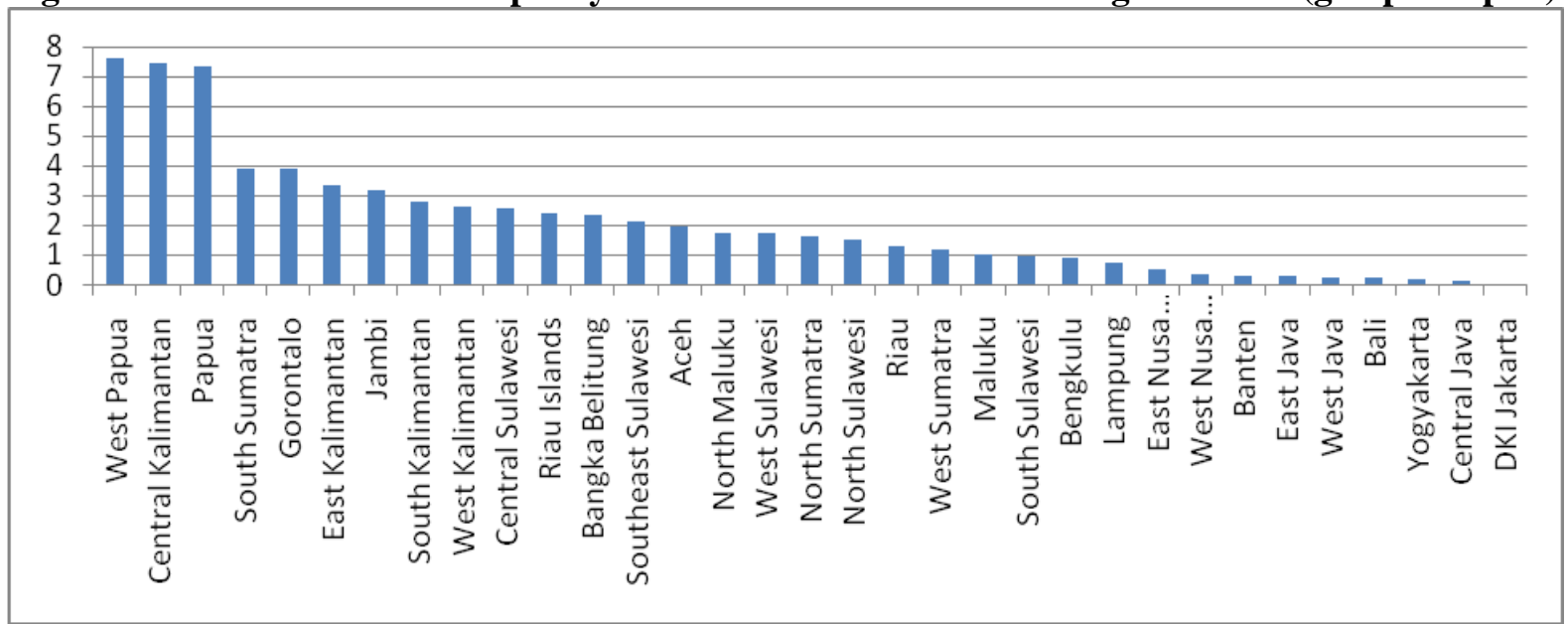

Source: Calculated based on the Indonesian Ministry of Work (2010)

Particularly, to analyze contradiction and CCC we employ a relative classification of ecological capital levels among provinces, using four groups: Very High Ecological Capital (VHEC), High Level Ecological Capital (HEC), Medium Ecological Capital (MEC) and Low Ecological Capital (LEC). Each group contains a quartile of the provinces. All permutations of CCC and contradiction in the structural linkages of economic growth to ecological capital are shown in Table 2 below.

Table 1 CCC and Contradiction: Economic Factor and Ecological Capital

\begin{tabular}{|c|c|c|c|c|}
\hline \multirow{2}{*}{ Economic Factor (GDP growth per capita) } & \multicolumn{4}{|c|}{$\begin{array}{l}\text { Ecological Capital (Biocapacity minus Ecological } \\
\text { Footprint) }\end{array}$} \\
\hline & VH & $\mathrm{H}$ & M & $\mathrm{L}$ \\
\hline High & ++ & ++ & $\mathrm{C}$ & $\mathrm{C}$ \\
\hline Medium & $\mathrm{C}$ & $\mathrm{C}$ & ++ & $\mathrm{C}$ \\
\hline Low & C & C & C & -- \\
\hline
\end{tabular}

Table 1 displays the performance of all Indonesian provinces in terms of both the GDP per capita growth rate (high, medium or low) and the change in ecological capital during the decade of the 2000s. The row of CCC lists provinces that experience cumulative causation in the linkage of factors in the decade. All of these are cases of positive feedback between economic growth and improvement in ecological capital (indicated by + ). The 
contradictions at the provincial level are listed in the row of contradiction. Percentages of provinces that experience $\mathrm{CCC}$ and/or contradiction are also presented in the table, to show the pattern of linkages.

Table 2 Structural Linkage of Ecological Capital and Economic Factor (GDP growth per capita) in Indonesia, 2000s

\begin{tabular}{|c|c|}
\hline & \\
\hline & $2000 s$ \\
\hline High growth & $\begin{array}{l}\text { Aceh-MEC, North Sumatra-VHEC, Jakarta-LEC, West Java-MEC, } \\
\text { Central Java-LEC, East Java-LEC, Bali-LEC, Banten-MEC, West } \\
\text { Sumatra-HEC, Jambi-LEC, Riau Island-VHEC, South Sumatra-VHEC, } \\
\text { Lampung-MEC, South Kalimantan-HEC, East Kalimantan-VHEC, North } \\
\text { Sulawesi-MEC, Central Sulawesi-VHEC, South Sulawesi-HEC, West } \\
\text { Nusa Tenggara-MEC, West Papua-VHEC, Papua-VHEC }\end{array}$ \\
\hline Medium growth & $\begin{array}{l}\text { Yogyakarta-LEC, Riau-LEC, Bangka Belitung-HEC, Bengkulu-LEC, } \\
\text { West Kalimantan-VHEC, Central Kalimantan-VHEC, Gorontalo-VHEC, } \\
\text { West Sulawesi-HEC, East Nusa Tenggara-MEC, Maluku-MEC, North } \\
\text { Maluku-HEC }\end{array}$ \\
\hline Low growth & Southeast Sulawesi-HEC \\
\hline $\mathrm{CCC}$ & $\begin{array}{l}\text { North Sumatra (+),West Sumatra (+), South Sumatra (+), South Kalimantan } \\
(+) \text {, East Kalimantan }(+) \text {, Central Sulawesi (+), South Sulawesi (+), Papua } \\
(+) \text {, East Nusa Tenggara }(+) \text {, Maluku (+), West Papua (+), Riau Island (+) }\end{array}$ \\
\hline $\begin{array}{l}\text { Number of provinces } \\
\text { (percentage in } \\
\text { bracket) }\end{array}$ & $12(36.36 \%)$ \\
\hline Contradiction & $\begin{array}{l}\text { Aceh, DKI Jakarta, Central Java, West Java, East Java, Bali, Jambi, } \\
\text { Lampung, North Sulawesi, West Nusa Tenggara, Yogyakarta, Riau, } \\
\text { Bengkulu, West Kalimantan, Central Kalimantan, Southeast Sulawesi, } \\
\text { Gorontalo, North Maluku, West Sulawesi, Bangka Belitung, Banten }\end{array}$ \\
\hline $\begin{array}{l}\text { Number of provinces } \\
\text { (percentage in } \\
\text { bracket) }\end{array}$ & $21(63.64 \%)$ \\
\hline $\begin{array}{l}\text { Sol } \\
\text { Sul } \\
(20\end{array}$ & $\begin{array}{l}\text { is calculated using period annual averages based on Hill (2008) } \\
\text { eriod annual averages based on Indonesian Ministry of Works } \\
\text { logical Capital, MEC: Medium Ecological Capital; LEC: Low } \\
\text { inus ecological footprint) were calculated using quartile method }\end{array}$ \\
\hline
\end{tabular}

Table 2 supports three major stylized facts with respect to structural linkage between ecological capital and economic growth in Indonesia. The first is that contradiction dominates the structural linkage between ecological capital and economic growth at the provincial level during the first decade of the 2000s. The second stylized fact is that both CCC and contradiction occur at the provincial level in a heterogeneous geographical pattern. Several provinces in western Indonesia, such as North Sumatra, West Sumatra and South Sumatra, experience CCC, while some provinces in eastern Indonesia, such as South Sulawesi, Central Sulawesi, Papua and Maluku, also experience CCC. Furthermore, contradictions occur in 
several provinces in eastern Indonesia, for example Gorontalo, West Sulawesi, Southeast Sulawesi and North Maluku, while some provinces in western Indonesia, such as Aceh, DKI Jakarta, Central Java and East Java, also experience contradiction. The third stylized fact is that the process of CCC is dominated by 'positive-positive' patterns with 12 provinces that experience 'positive-positive' of CCC and no provinces having 'negative-negative' patterns.

In terms of C-SP-P structural linkages, heterogeneous patterns of contradiction at the Indonesian provincial level show that many core and semi-peripheral or peripheral provinces lack capacity to benefit from regional institutions. Even though core provinces use regional institutions to control structural linkages, DKI Jakarta, East Java and Central Java experience high economic growth and a relative decline ecological capital. These provinces are unable to extract enough biocapacity from semi-peripheral and peripheral provinces to generate economic growth without eroding their own ecological capital.

In semi-peripheral and peripheral provinces, various patterns can be identified in Table 2. West Papua and Papua have 'positive-positive', suggesting CCC with relatively high levels of both economic growth and ecological capital change. Yet, these provinces are potentially under control of the core provinces. Modest CCC occurs in Maluku and East Nusa Tenggara, with moderate economic growth and moderate improvement in ecological capital. Southeast Sulawesi and North Maluku are in the group of semi-peripheral and peripheral provinces that have positive ecological capital change yet are unable to derive benefit from their reserves in terms of achieving high economic growth.

\section{Conclusion}

This study investigates the uneven pattern of ecological capital change at the provincial level in Indonesia. The principles of political economy are used to link the pattern of ecological capital change to economic performance. The findings of the study are summarized into three conclusions.

The first conclusion is that an uneven pattern of ecological capital arises from the structural linkages between core and semi-peripheral or peripheral provinces. The regional institutions of ecological capital typically are held sway over by a group of core provinces. This shows that the balance of hegemonic institutions in Indonesia is unfavorable to the periphery. The unbalance hegemonic institution in Indonesian provinces generally implies a 
sustainable gap of socioeconomic development between provinces in western Indonesia and provinces in eastern Indonesia.

The second conclusion is that contradictions in the structural linkage between economic development and environmental factors occur at the provincial level, with increasing economic growth leading to declining ecological capital. Ecological capital reserves in some semi-peripheral and peripheral provinces combine with relatively low economic growth. This shows the ability of core provinces to use institutions to control the biocapacity of semi-peripheral and peripheral provinces. However, this situation implies that the socioeconomic development gap between western and eastern provinces in Indonesia is caused by the institutional gap between them.

The institutional gap between western and eastern provinces in Indonesia is sourced by some basis. First, historical basis shows that western provinces of Indonesia are the center of education and technological development. As Myrdal's CCC model shown, an area with high educational community typically generates potential employments. Second, potential employments in the western provinces of Indonesia have high probability to achieve wealth access. Third, the equality of wealth access in the western provinces of Indonesia is relatively high to the eastern provinces. This situation is likely to promote income polarization in the western provinces. Consequently, western provinces become core provinces that control public policy in Indonesia, especially natural resources.

The third conclusion emphasizes heterogeneity in the regional pattern of ecological capital in Indonesia. Contradictions occur in many core provinces in Java Island, more than half the provinces of Sumatra Island, in a half part the provinces of Kalimantan Island as well as Bali and Nusa Tenggara. The process of CCC is experienced by only one-third of total Indonesian provinces, including West Sumatra, Riau Islands, East Kalimantan, South Sulawesi and Papua.

The third conclusion generally supports contradiction model in Figure 4. It appears that core provinces (e.g. provinces in Java) use institutions to control the ecological capital in semi-peripheral and peripheral provinces (e.g. non-Java provinces), using the latter's natural resources to support the economic development of the core provinces. Although core 
provinces have hegemonic institutions, they still generally experience contradiction between sustainable ecological capital and economic development. On the other hand, the relatively high ecological capital in peripheral provinces does not lead to economic development. 


\section{References}

Amin, Samir. (1972). "Underdevelopment and Dependence in Black Africa: Historical Origin". Journal of Peace Research, Volume 9, (Number 2):pp. 105-120.

Argyrous, George. and Bamberry, Geoff. (2009). "Cumulative Causation and Industrial Development". In The Foundation of Non-Equilibrium Economics: The Principle of Circular and Cumulative Causation, edited by S. Berger. New York: Routledge.

Arrighi, Giovanni., Silver, Beverly J. and Brewer, Benjamin D. (2003). "Industrial Convergence and the Persistence of the North-South Divide". Studies of Comparative International Development, Volume 38, (Number 1):pp. 3-31.

Baran, Paul A. (1957). The Political Economy of Growth. New York: Monthly Review Press. Bell, Daniel. (1976). The Cultural Contradictions of Capitalism. New York: Basic Books.

Berger, Sebastian. (2008a). "K. William Kapp's Theory of Social Cost and Environmental Policy: Toward Political Ecological Economics". Ecological Economics, Volume 67:pp. 244-252.

. (2008b). "Circular Cumulative Causation (CCC) a la Myrdal and Kapp-Political Institutionalism for Minimizing Social Cost". Journal of Economic Issues, Volume XLII, (Number 2):pp. 357-365.

. (2009). "Circular Cumulative Causation ala Myrdal and Kapp". In The Foundation of Non-Equilibrium Economics: The Principle of Circular and Cumulative Causation, edited by S. Berger. New York: Routledge.

Boulding, Kenneth. (1984). The World as A Total System. United States: SAGE Publisher.

Burkett, Paul. (2006). "Two Stages of Ecosocialism". International Journal of Political Economy, Volume 35, (Number 3):pp. 23-45.

Foster, John Bellamy. (2005). "The Treadmill of Accumulation:Schaiberg's Environment and Marxian Political Economy". Organization Environment, Volume 18, (Number 7):pp. 7-18.

Frank, Andre Gunder. (1967). Capitalism and Underdevelopment in Latin America. New York: Monthly Review.

Glyn, Andrew. (1990). "Contradictions of Capitalism". In The New Palgrave: Marxian Economics, edited by J. Eatwell, Milgate, M. and Newman, P. London: MacMillan. . (1997). "Does Aggregate Profitability really matter?". Cambridge Journal of Economics, Volume 21:pp. 593-619.

Goosens, Yanne, et.al. (2007). "Alternative Progress Indicator to Gross Domestic Product (GDP) as A Mean Towards Sustainable Development". Working Paper European Parliament's Committee on the Environment, Public Health and Food Safety:pp. 1-95.

Hill, Hal. (2008). "Indonesia's Changing Economic Geography". Bulletin of Indonesian Economic Studies, Volume 44 (Number 3):pp. 407-435.

Indonesian Statistical Board. (2010). Indeks Pembangunan Manusia Propinsi dan Nasional 1996-2010. Jakarta: Indonesian Statistical Board (Badan Pusat Statistik Rep. Indonesia).

Indonesian Ministry of Works. (2010). Ecological Footprint in Indonesia. In Indonesian Ministry of Works Report. Jakarta: Indonesian Ministry of Works.

Kaldor, Nicholas. (1957). "A Model of Economic Growth". The Economic Journal, Volume 67, (Number 268):pp. 591-624.

Kapp, Karl William. (1963). The Social Cost of Business Enterprise. Nottingham, UK: Spokesman Book.

Korzeniewicz, Roberto P. (2001). Core-Periphery Analysis. In Encyclopedia of Political Economy, edited by P. A. O'Hara. London and New York: Routledge. 
Marx, Karl. (1885). Capital: A Critique of Political Economy. Vol. Volume II. Moscow: Progress.

Myrdal, Gunnar. (1944). An American Dilemma. New Jersey, United States: Harper and Row.

(1968). Asian Drama: An Inquiry into Poverty of Nations. 3 vols. New York: Twentieth Century Fund.

O'Connor, James. (1994). "Is Capitalism Sustainable?". In A Guilford Series-Conjuction with Political Economy and the Politics of Ecology. New York, United States: The Guilford Press.

O'Hara, Philip A. (2007). "Principles of Institutional-Evolutionary Political EconomyConverging Themes from the Schools of Heterodoxy". Journal of Economic Issues, Volume XLI, (Number 1):pp. 1-42.

. (2010). "Core General Principles for the Revival of Political Economy". In Third Plenary Session on "The Revival of Political Economy", as part of the The Revival of Political Economy: Prospects for Sustainable Provision, Coimbra Conference 2010, . Faculty of Economics, University of Coimbra, 21-23 October 2010.

Polanyi, Karl. (1944). Great Transformation. United Kingdom: Oxford University Press.

Prebisch, Raul. (1950). The Economic Development of Latin America and its Principal Problems. New York: United Nations.

Salim R., S. Rafiq and A. F. M. K Hassan (2008) "Causality and Dynamics of Energy Consumption and Output: Evidence from Non-OECD Asian Countries", Journal of Economic Development, Volume 33: 1-26

Schumpeter, Joseph A. (1939). Business Cycle I-II. London: McGraw-Hill.

Sen, Amartya. (2011). On Economic Inequality: OUP Catalogue.

Wallerstein, Immanuel. (1979). The Capitalist World Economy. Cambridge: Cambridge University Press. 